\title{
Doing Justice to Stories: On Ethics and Politics of Digital Storytelling
}

\author{
NASSIM PARVIN \\ GEORGIA TECH
}

\begin{abstract}
Researchers and activists are increasingly drawing on the practice of collecting, archiving, and sharing stories to advance social justice, especially given the low cost and accessibility of digital technologies. These practices differ in their aims and scope yet they share a common conviction: that digital storytelling is empowering especially when curating and disseminating life stories of marginalized groups. In this paper, I question this conviction and ask: is it possible that such practices take away from what is found to be meaningful and worthwhile in practices of storytelling and listening, and, if so, how? To answer this question, I argue for a renewed attentiveness to story scenes, highlighting the inherently relational nature of storytelling and listening. I examine this relational nature through a fictional account that exemplifies storied encounters and demonstrates the ethical issues they entail through three themes-reciprocity, responsiveness, and communion-borne out of the plurality of philosophical positions on what it means to relate to another. I explain each of these themes as a starting point for thinking through how digital storytelling may be just, with implications for participatory methods in science and technology studies, design studies, and human-computer interaction inclusive of participatory design, co-design, ethnographic research, and participatory action research.
\end{abstract}

\section{Keywords}

digital storytelling; digital archives; storytelling and listening; big data; participatory methods; ethics and politics of digital storytelling; social justice

${ }^{1}$ Nassim Parvin, Email: nassim@gatech.edu

Copyright (C) 2018 (Nassim Parvin). Licensed under the Creative Commons Attribution Non-commercial No Derivatives (by-nc-nd). Available at estsjournal.org. 


\section{Introduction}

I love StoryCorps. ${ }^{2}$ Yet, I change channels or turn off the radio most times that one of the stories is played on air. It is not that I am not drawn to the stories. Rather, I feel insufficiently prepared to enter the intimate spaces of the stories that happen to be playing on air when rushing to work in the morning, or worrying about unanswered emails in the afternoon. There is an inherent contradiction in this because, on the one hand, I am convinced that making myself available to another is ethical (Frank 2010, 95), yet, on the other hand, the ethical thing to do, at least in some circumstances, may be just the opposite.

Beyond daily individual encounters, I am drawn to the larger collective work of projects such as StoryCorps-recording conversations about personal relationships and connections and documenting everyday joys and pains, hopes, and aspirations. At the same time, it is my fear and concern that the capacity to record, archive, and share stories-proliferated through the availability of digital tools and technologies—can render them flat or, even worse, turn them into commodities.

I do not mean this as a nostalgic plea for a simpler time when stories were told and listened to in their own time and place. I am well aware of the collective power of stories as a force for social change and even strengthening democracy (Lambert 2013 [2006]; Couldry 2008). I also wonder what we might know if we had similar accounts of the everyday from centuries ago and appreciate their values as a form of collective memory. For these reasons, I am grateful for technologies that enable the recording and archival of individual and group stories in ways that are unprecedented.

But is it possible that the same collective force that is gained through digital storytellings masks and even betrays stories, taking away from what is meaningful and worthwhile in the acts of storytelling and listening?

As a design scholar working at the intersection of digital media and STS on projects that strive to advance social justice, I encounter the problem of collecting, archiving, and sharing stories often, especially in the immediately adjacent fields of Human Computer Interaction (HCI) (e.g., Dimond et al. 2013; Ahmed et al. 2014) and media studies (e.g., Couldry et al. 2015). For example, it is not uncommon for HCI researchers to approach marginalized communities as a way to think through the digital tools that might either advance the particular needs of the community or assist in ethnographically describing it. In such contexts, it soon becomes clear that digital technologies fail as "solutions" to the often-systemic economic and sociopolitical barriers

"Storycorps (pronounced "story core") is a non-profit oral history project in the United States with the aim of recording and archiving stories of everyday Americans in the form of conversation between two people. The National Public Radio (NPR) broadcasts selected stories weekly.

${ }^{3}$ A working definition of digital storytelling is offered by Couldry $(2008,374)$ understood as "the whole range of personal stories now being told in potentially public form using digital media resources."

" Readers interested in additional examples of such work in HCI, see, for example, Capel, Taylor, and Vyas (2016), Clarke et al. (2013), Fox and Le Dantec (2014), Herron et al. (2016), and Strohmayer et al. (2017). These researchers, along with Bardzell and Bardzell (2011), Dombrowski, Harmon, and Fox (2016), CostanzaChock (2011), Durrant, Kirk, and Reeves (2014), Light and Akama (2012), Nathan et al. (2017), and Taylor (2011), are among scholars in this field who have written about some of the challenges and tensions of social justice research in the context of technology design and assessment. 
that communities face. Researchers observe, however, how openly and eagerly the communities share their stories and contend that the process itself is meaningful and worthwhile in that they help participants reflect on a particular situation or life event, or forge new connections. They further note that many of the individuals and collectives they meet appear to be looking for ways to make their voices heard and their stories known. Relatedly, these researchers note how the encounters and experiences changed their own perspectives and preconceptions, arguing that connecting people across class, social, and cultural barriers through digital technologies will have similar transformative effects.

Collecting, archiving, and sharing stories, then, are identified as productive practices to advance social justice, especially given the low cost and accessibility of digital technologies. Think, for example, of a digital tool that might enable an immigrant community to tell its stories of strife and hardship living as undocumented workers or facing deportation. Or, imagine a digital bulletin board that would enable refugees to share their stories, documenting hardships, challenges, and helpful resources. Such tools, the argument goes, could alleviate some of the isolating aspects of individual experiences and create a sense of community and solidarity. Moreover, the stories could be shared with the larger community to humanize those who are marginalized, secure resources to help them meet their day-to-day needs, or serve as a catalyst for political change. The collection of stories also holds inherent value as an archive, saved for present and future generations who can access and mine it for a variety of purposes.

But what do we owe to stories? Asking this question serves as an entry point to both critique and advance digital storytelling practices that strive to be just and advance social justice. In response, I put forward the hypothesis that doing justice to stories rests on reconnecting stories to story scenes, ${ }^{,}$broadly defined here as the very particular settings of storytelling and listening. Doing so, I argue, draws attention to the inherently relational nature of storytelling that is key to doing justice to stories. I examine this relational nature by showing how it may be understood through three ethical themes-reciprocity, responsiveness, communion-borne out of the plurality of philosophical positions on what it means to relate to another. Each of the themes brings to light a different aspect of what it may take to do justice to stories. Taken together, reciprocity, responsiveness, and communion demonstrate how focusing on the relational nature of storytelling and listening is a productive way to engage the ethical weight of understanding the uses (and misuses) of digital storytelling.

In what follows, I share a fictional account that marks both the centrality of story scenes and the significance and fragility of relationships that unfold through acts of storytelling and listening. I have crafted this account based on my many experiences-as a participant, reviewer, scholar, and educator-encountering variations of such initiatives. As such, and aligned with the ethos of feminist scholarship (e.g., Chin 2016; Forlano 2017; Jain 2013), my own experiences, histories, and embodied understandings are entangled in this argument.

${ }^{5}$ Many scholars, including Judith Butler (2005), Adriana Cavarero (2014), and Arthur Frank (2000), talk about story scenes/narrative scenes. None, to the best of my knowledge, have related story scenes to the ethics of storytelling and listening. 
I have deliberately chosen to explore a fictional example, and not to anchor my present analysis on actual digital storytelling projects, for several reasons. First, unlike ethnographically oriented STS scholarship that is more and more reflexive of its processes and interventions (e.g., Callison 2014; Foster 2017; Wylie 2018), existing actual projects often do not document the processes that work in the background of collecting and archiving stories More specifically, the details and nuances of story scenes are often missing. Second, the point of this paper is not to criticize specific projects but rather to highlight the issues of justice that pertain to such practices in general.

I begin with a story that helps construct an actual scene of human interaction. Fiction can be an effective way to draw out what other methodological approaches may rule out of their purview (e.g., Subramaniam 2014, 70-95). Moreover, by constructing a scene of human interaction, this method seeks "the formation of a sympathetic imagination for human relations in action [...]" (John Dewey cited in Siegfried $(1996,224)$ ). In other words, the story draws attention to the concrete emotional and intellectual character of life situations and qualities that are otherwise lost in abstract values of moral conduct. Aligned with this observation, the ethical considerations developed here are not meant as rules of conduct or value checklists. They are rather intended as beginnings for a better understanding of what is at stake in digital storytelling practices. Picture, for example, the story scenes of a project aimed at collecting, archiving, and sharing stories of a neighborhood.

\section{So, tell me your story... Corner store}

Tyler has lived all his life in a distressed neighborhood that a powerful industry picked as a site for dumping hazardous waste two years ago. There are unofficial reports of people getting sick more often. Those who have the means are leaving the neighborhood. One grocery store recently closed and other small businesses are struggling. There are even rumors that the only high school in town will be closing soon.

At age thirty-four, Tyler feels privileged to run the small convenience store that his uncle left behind a few years ago when his dementia was no longer manageable. He grew up in the store and knows well how to run the business to sustain both his and his uncle's families. And while everything around him seems to have been collapsing since his mom's passing and his uncle's dementia, he still takes pride and joy in the store. He knows almost everyone in the neighborhood, including the children who come to his store in bursts after school for lollipops or other treats.

Against this backdrop, a young woman visits his store one day, telling Tyler that she is interested in his story as related to the waste site. Her name is Beth and she is with a group of researchers working on a project to bring awareness about the issues facing the neighborhood. As part of this project, she asks Tyler to share his story.

She appears sincere. 
Tyler agrees to meet with her and share his story-at least a story. It is not because other people have not asked for or told these stories. There was actually an influx of reporters, researchers, and business people turning their gaze toward the neighborhood, especially leading up to and soon after the introduction of the waste site. Yet, the interest quickly wore off-and it seems that no one is paying attention anymore. So, Tyler decides it may be good to tell the story again, from his perspective, to let the world know what is going on. He might tell Beth about the neighbors who left. He might tell her about the school. He might describe the cases of children he knows from his convenience store who are getting sick.

Tyler and Beth meet at his store. Beth answers Tyler's questions, clarifying whom the story is for and how it will be used in her project. Tyler is curious if the story will be part of a reporting about industrial waste, as is usually the case. If so, he might talk about the negative impacts and what can be done to stop or reverse the decline. It turns out, however, that Beth is creating a kind of exhibition about the neighborhood. So, he needs to think of other things to say. His first instinct is to highlight the wellness and resilience of the community. After all, the descriptions of this neighborhood often center on lack and deprivation. So, he tries to capture the music, the food, the friendships, although it is hard to escape how all of those have been sabotaged and deteriorated since the waste site was set up.

Tyler pays attention to Beth's responses as he speaks-Does Beth appear to be understanding what he has to say? Does she know where it is all coming from? Is she following the story the way he intends? What will she really do with the stories? To Tyler, Beth seems privileged yet drawn into the story. She seems sincere and trustworthy, so he continues.

Beth asks more probing questions. Tyler struggles for words, for a coherent narrative. He is struck by how much he doesn't know. He finds it difficult and at times painful to weave the many threads of the sequence of events. He would like to have more time to think through the answers to her questions. What does he really want to say? What story is worth telling? What story might do most good when it gets out there? He wants to know more about what she is looking to capture and what she will do with all of it. He starts worrying about what he has said, his choice of words, his selection of issues that matter, his depiction of the neighborhood.

Tyler notices that the allocated time for the interview is up. He's relieved.

\section{Gallery}

It has been almost a year. Tyler is going to the opening of the show that features his story, among others. He does not go to museum events frequently. He finds them to be detached and not welcoming. The last time he visited the art museum he felt so out of place that he left in less than twenty minutes. But he hopes this one will be different since it is Beth's show, and so also his show. The gallery is set in the part of town that was once a manufacturing hub connected to railroads, then hit by recession, waves of unemployment, and decline. It was recently recovering though and, some might say, being gentrified. The inside of the gallery is like most gallery spaces: white and pristine. As he enters, Tyler feels his heart beating faster. Traces of the building's industrial past remain on the ceilings. Around the room there are names printed in 
bold on the walls: Dina, Telah, Jordan, Malik, Gail. Each name marks a framed picture of a closeup image. Dina's is next to a close-up image of old hands knitting something in thick, bright-red yarn. Tyler can see a child's feet in mismatched socks hanging from a rocking chair next to Telah's. There are also photographs of boots, a typewriter, and a swing. Tyler quickly recognizes the image of child's hand holding a lollipop against the blurry but distinguishable background of the shelves in his store. There is his story!

Tyler counts twenty-one frames. Underneath each, there are headphones with simple controls. He is hesitant to listen to his own story so he approaches another. This one is tagged "Gail" next to an image of an old violin. Tyler puts on the headphones and starts listening. Gail is recalling her childhood, growing up with her grandparents. She describes their house and her friends when Beth, tapping gently on Tyler's shoulder, interrupts his listening. She welcomes him and offers to give him a tour. They move around, stopping at a few of the frames as Beth shares a memorable anecdote or describes her first encounters with the participants. She tells him how the most rewarding part of the work for her was the friendships that she formed - that she now has a different appreciation for the community and better understanding of what they are going through, and that she wishes her audience to have a similar experience. She points him to a screen at the end of the gallery. As they walk toward it, she explains that she wanted the stories to speak for themselves, so she did very little editorial work. She draws his attention to a digital map that can be accessed through the web, where she juxtaposed the stories onto where they originated. Another view brings up short clips of everyone's responses on specific themes. To Tyler's dismay, waste site and despair are among the themes appearing in large type beside his story location.

Tyler notices a visitor approaching his section. He keeps her in his periphery, trying to keep track of her facial expressions to get a sense of her response to the story while playing with the map. He wonders if he might know some of the other people who are marked on the map. He puts on the headphones and clicks on one and a short summary appears in a text box. He clicks on the audio link, which seems to be broken. At this time, he notices that the woman who was listening to his story is walking away. Did she lose interest? Was he boring? He remembers how disjointed his reflections were and wishes that Beth had helped him craft his piece. She was so articulate! Maybe he can summon the courage to listen to his own story; or maybe he can ask one of his friends for their honest opinion about it.

Tyler clicks on another link. This one seems to be working. But he stops it before it gets to the end of the first sentence. He is not in a mental space to listen to the story and he doesn't want to ruin it or hurt the feelings of the teller in case she is around. He tries to find Beth to say goodbye but she seems busy talking to a few people. Tyler walks to the door, ambivalent about the experience. He is unsure if he would do this again had he been able to redo it. The thought that's bugging him now is how he could tell the story better-and what is the story anyway? Maybe he should listen to those other stories; maybe that would help him figure it out!

He also wishes he had gotten to know Beth better. It was so different to see her in the gallery. He wonders what her story is: why did she want to work on this project? What is she going to do next? Maybe he can ask her once she is back from sabbatical. 


\section{Story Scenes: The Relational Nature of Storytelling and Listening}

What do we owe to stories? To answer this question, it is crucial to reconnect stories to the

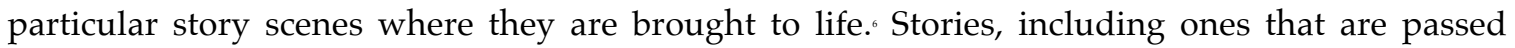
through generations, reside in time and place, always implying a teller and a listener (or tellers and listeners) within a conversational situation. This is particularly true for life stories that develop as one attempts, in Judith Butler's (2005) words, to "give an account of oneself." One might find evidence of this in the story scene above, for example, where Tyler's account is formed in his encounter and conversation with Beth.

Reconnecting stories to story scenes foregrounds the relational nature of storytelling and listening in its many subtle layers. In doing so, it opens up the possibility of a renewed attentiveness to what we owe to stories in their relational and entangled positions within the very particular story scenes in which they are brought to life.

Being attentive to the relational nature of storytelling and listening, in turn, serves as a focus enabling us to think through the constitutive role of digital technologies in framing, disrupting, and distorting stories, even as they make mediated story scenes possible. The very existence of digital storytelling projects rests on the tacit assumption that story scenes are irrelevant or at best incidental to stories. In this manner, digital technologies risk reducing storytelling to a mechanical process of information exchange assuming that all there is to storytelling and listening is capturing, sharing, and disseminating the contents of a story.

The story scene above illustrates more ways that digital storytelling can be interrupted, broken, and unfulfilled at all stages of conception, development, archival, and distribution. The presence of a recording device, for example, radically changes the story scene, partly by anticipation of permanence and partly by extending the address to include anticipated audiences. Recording and sharing stories displaces stories in ways that allow them to lose connection with the original story scenes that brought them to life. It is easy to see, for example, that the story scenes at the gallery, including the relational quality of listeners to the tellers, are very different to the scenes within which the stories were told. Relatedly, the ease of recording and sharing stories means that they can easily move out of context, finding themselves in settings that are entirely inappropriate to or even oppositional to their aims and purpose. On the one hand, for example, we may appreciate the use of the gallery space for facilitating the occasion of an intimate listening time and place devoted to each story. On the other hand, we can see how distant the gallery as a space and concept is from the people and stories it withholds.

Digital technologies offer the opportunity of collecting stories at a scale not possible with any other medium. This is a commonplace rationale of many digital storytelling projects. And indeed, the quantity and reach of stories is magnified through the use digital technologies. This

' Here, I use the verb to bring to life in a broad sense. For example, as Beth engages Tyler, a story is brought to life or born in conversation in the sense that it may not have been before the encounter or did not take the very particular form that it finds as the result of the very particular nature of the situation. A recorded story is brought to life in a different sense when someone listens to it within a particular setting with specific aims, attention, and openness to it. 
brings the risk, though, that digital storytelling too is turned into another manifestation of a fundamental belief in the inherent value of big data devoid of its context, not unlike what we see in other arenas such as health (Lupton 2014) or politics (Loukissas and Pollock 2016). The abstraction that occurs through archival and mass distribution has the potential to mask the meaning and purpose of those stories, turning them into a commodity to be mined, searched, edited, and consumed at will. These stories then reside in a saturated media landscape where so much is competing for our attention. Concerns about "compassion fatigue" and a selective engagement where we look for and interpret stories in ways that cement already held beliefs are particularly relevant (see Sontag 2003).

Lastly, the focus on digital distribution of stories centers attention on the collection practices as opposed to individual stories and the unsettled and unsettling issues that connect them together. In many cases, technology and its powers to search, sort, and map takes center stage especially when emerging technologies are used. There too, we see the many ways the storytelling and listening processes are disrupted and attentions are moved from the weight of the stories to the powers of technologies or future potentials of the archive.

The idea that technology is never neutral is fundamental to STS. Yet, in many digital storytelling projects, the neutrality of technologies is implicitly taken for granted-downplaying the ways that (digital) mediation shapes what stories are told and how, and rendering power dynamics invisible. But what is clear is that we cannot assume automatically and unproblematically that digital storytelling facilitates building strong relationships and expanding individual and collective understanding. Reconnecting stories to story scenes is critical, especially if we take seriously the concern that we are seeing a decline of culture of conversation where messy and demanding human relationships are replaced with fragmentary information collected from selective connections (Turkle 2016). What's at stake, not unlike other "memory practices" (e.g., Bowker 2005), is the impact of digital technologies on practices and experiences of storytelling that could be attentive to the content, form, reach, and influence of stories.

In what follows, I describe the ethical issues held within storied relations under three themes: reciprocity, responsiveness, and communion-each gesturing toward one of the facets of justice that is central to the practices of storytelling and listening. Together, they help expand our understanding of what's at stake in digital storytelling and listening beyond a mere preoccupation with collection, archiving, and distribution. These themes are not meant as mutually exclusive categories but rather as conjoined places where issues of justice in practices of collecting, sharing, and archiving stories may be identified and examined.

\section{Reciprocity}

At a common sense level research was talked about both in terms of its absolute worthlessness to us, the indigenous world, and its absolute usefulness to those who wielded it as an instrument. It told us things already known, suggested things that would not work, and made careers for people who already had jobs. Linda Tuhiwai Smith, Decolonizing Methodologies: Research and Indigenous Peoples 
Taking the starting point in the economic view of social relations, we might characterize storytelling and listening as processes of material exchange, which points to one sense of justice that I capture under the theme of reciprocity. Reciprocity brings out, for instance, the need for transparency about the framing and scope of the project and clarity about what each person might be expected to do. It highlights the potential gains and risks and their uneven distributions. It also raises awareness about rights, mutual expectations, and contingencies.

In the scenario above, for example, Tyler agrees to share his story with aims that are intangible and may or may not be materialized. The most important gain for him is that the story that he wants to tell is actually captured and told. This is a story that has the capacity to serve as a window into Tyler's life and his community and, possibly, to live beyond both. We might recognize, however, clearer and more immediate tangible gains for Beth, who is there to collect stories. These gains have to do with her professional career, institutional rewards, and social status. Beth approaches Tyler with the material and political luxuries that make it possible for her to show up and ask questions. Tyler is tasked with responding to her questions within the specific frame of Beth's project, the contours and aims of which are largely unknown to himincluding the ways that they may be adjusted or recrafted to better suit his purposes.

This is not to claim that the act of storytelling is entirely without gains for Tyler. He gains access, albeit momentarily, to a political and social realm more powerful than his own, as he can potentially reach those who would not ordinarily have interest or care enough to listen to his story. He can share his understanding and concerns in his own voice. There is even the possibility of changing minds or affecting change. Beyond that, the chance encounter might constitute an even bigger shift. What if a major news outlet picks up the story? What if it draws the attention of a philanthropist or politician who can provide resources? And if none of that, he now has a connection that might be useful in the future. All of these could be understood as potential gains.

Considering reciprocity as a starting point for understanding the relationships mediated by storytelling surfaces important issues related to the give-and-take in these relationships.' Far from what common tropes of empowerment and giving voice suggest, surfacing reciprocity in the context of such projects reveals the ways in which researchers/artists/curators who collect stories are positioned to gain a lot more in these exchanges than the communities whose stories are collected and shared. In doing so, and in spite of their intentions to highlight social issues or bring about social change, these projects even risk a continuation of extraction practices and a commodification of the stories of marginalized groups. These practices are most beneficial to the curator, artist, or researcher and risk advancing unjust practices that are recognized as colonial. Indeed, the sentiment that Smith (2013) is highlighting in the quote preceding this section finds parallels in the practices of collecting, archiving, and sharing of stories. Reciprocity is a dimension of justice that may help anticipate, address, and mitigate some of such injustices.

Thinking through the reciprocity of storytelling and listening is also productive of how we engage with recorded stories as listeners. We might remember, for example, that stories are

- For a nuanced account of possibilities, demands, and obligations of reciprocity in qualitative research through concrete cases, see Harrison, MacGibbon, and Morton (2001). 
tethered to time and place. So, we might consider the time and the social setting from which they emerge, being inquisitive about when and where they come from, who their intended audiences were, and how their tellers might feel about how we listen to them. What are the terms of using those stories? For example, is it fair to weave the story into a political argument? What is our responsibility in protecting its intended meaning? How can we make sure that it is not altered or misused by a different or perhaps hostile audience? In doing so, reciprocity opens up a space for considering issues related to ownership, transparency, and mutual consent with respect to how stories might be used, altered, or (re)framed. More broadly, what do new story scenes do to the content, form, and intended purposes of stories?

It is important to note, however, that while reviving the importance of reciprocity can be important when considering the ethical weight of storytelling and listening, in action it may be misconstrued as a contract that settles the case once and for all. This is a grave mistake. Even if we were to reduce storied relations to an economic process of information exchange, doing justice to stories should be viewed as an ongoing reflection on the give-and-take-one that can be shifted and adjusted as the relationship unfolds. This pitfall of such a transactional view of the storytelling and listening also points to the limits of the idea of reciprocity to address other aspects of justice that are integral to it, as explained below.

\title{
Responsiveness
}

\author{
Let us remember that one gives an account of oneself to another, \\ and that every accounting takes place in the context of an address. \\ I give an account of myself to you. \\ Judith Butler, Giving an Account of Oneself
}

An understanding of justice highlighted by reciprocity could limit our appreciation of what's at stake in collecting and sharing stories, as it leaves out qualities of relationships that are mediated in the acts of storytelling and listening. That could risk reducing the relational nature of storytelling and listening to a transactional process, starting with the assumption that stories are ready-made commodities for exchange and that consent—-that is others' willingness to share their story-is sufficient for doing justice to stories.

Stories, however, are not ready-made commodities of exchange. They are contingent social processes and emergent accounts that depend on the nature and quality of the encounters that bring them to life. Recognition of the partial and open nature of stories and the uncertainty and vulnerability that characterize story scenes points to a different dimension of justice that I refer to as responsiveness.

To assume that Tyler's story is one that can be told and recorded once and then archived and shared with multiple audiences is to consider him as essentially narratable. Following Butler (2005), however, it is important to remember that an ethical understanding of being human entails, in part, the acceptance of the lack of narratibility. This is not to question Tyler's character or honesty but to acknowledge that our understanding of ourselves is partial and deeply 
intertwined with the broader social and historical world that molds who we are in ways that we may not be able to fully grasp. It would indeed be a form of violence to view Tyler or any other human being as transparent, rational, and continuous (Butler 2005).

The texture of the story that is woven together within Beth and Tyler's encounters is at once constituted by and constitutive of the story scene. The story is particular to a time and place, to a language, and to a relationship that is unfolding. Who these people are in relationship to one another and what compels them to tell a story determines both its content and its form. This particular story, while honest and truthful, is not the same as the one Tyler might tell if Beth were an old friend who was visiting after years of being away or an inquisitive tourist visiting for the day. The story scene also extends beyond the spaces of encounter in the store or gallery. It encompasses the historical trajectories of domination and oppression, of privileged accounts and silenced narratives.

Tyler finds himself in an encounter with Beth, who belongs to a world largely unfamiliar to him. He is tasked with making sense of and engaging this world through his responses to Beth's questions, which makes him uncertain and vulnerable. He is aware, for example, of how prolific distorted stories and images of his community are, often portraying it mainly by its poverty or other kinds of deficiencies and deprivations. Tyler needs to be responsive to Beth in a manner that ensures her continued interest, both in the literal sense of responding to her questions and in the broader sense of being there and being responsive to the demands of her presence and her project. He is well aware of the delicate balance he needs to maintain to both restore the dignity of his community by foregrounding its wellness and resilience while at the same time underlining the injustices that it continues to endure. He needs to piece together a story while maintaining this balance through his answers to Beth's questions. Where can he begin?

In responding to Beth, Tyler is bound to leave some things out and emphasize others. He is likely to be unsatisfied and even doubt the story at the end. Not because he is uneducated, or naïve, or unreflective- or overwhelmed by the need to address both a real and imagined audience-but simply because he is human. He is compelled to participate in the project, though, as this is his chance to tell his story in the manner that is true to him and his community. In this sense, we can understand Tyler's desire to be narrated and might imagine his dependence on Beth (and her responsibility) to do it justice.

\footnotetext{
* To grasp this dimension of justice within story scenes, we might begin with feminist philosopher Cavarero's (2010) observation that there is a desire for narratability in each of us and a unique story is indeed possible since we are each a "unique existent." Yet we may not be able to tell our own stories, as, starting from birth, each of us depends on others for the narration of our own life story. And this is where our responsibility to one another lies. There are indeed two possibilities for us in relating to one another. The most immediate (and arguably unjust) one is to recognize the other for what they are, for example, via demographic categories of ethnicity, race, class, gender, and/or via social roles such as mother or teacher. But an alternative is possible and that is to see the other for who they are in their unique existence. It is in striving for the latter that we might capture another dimension of justice that I would refer to as responsiveness. It is also important to note that Cavarero's sense of this unique existence "is not one and the same as the individualism espoused by modern political philosophy. Rather, it is an existence that is exposed within the interactive scene of the world from birth" (Kottman 2014, ix).
} 
Tyler is vulnerable in that he depends, for the most part, on Beth for (re)telling his story in a way that is true to him and his community. He is unsure of where to start, what to talk about, and how to put all that he is thinking and feeling into words. He has to trust and depend on Beth-her presence, her questions, and her ability to present who he is to audiences that are wholly unfamiliar to him. He is not sure of how his story might be heard by different audiences-an uncertainty that permeates the whole process and is crystalized in the gallery scene.

We might also appreciate Beth making herself available to Tyler, especially at a moment when everyone else appears to be abandoning him and his community. She too is working within a fragile situation with many uncertainties. This takes courage, as she is an outsider. She is not sure, for example, about what Tyler's reaction may be. Will he be open to talking with her? What story might he share? How can she frame the questions to build trust and elicit meaningful stories? She is also vulnerable in staging an encounter of a different kind - both in the gallery and online. Will she be able to shape the multiple stories she collects into a cohesive whole? How would the people whose stories she is sharing respond? How might other audiences react?

An understanding of stories that recognizes their partial nature and dependence on story scenes is important for questioning the multiple assumptions that many projects aimed at collecting, sharing, and archiving stories commonly hold. For example, Beth's decision to include Tyler's audio with no manipulation and as little editing as possible may appear as one that is sensitive to honoring and preserving his voice. I would argue, however, that this assumption is particularly problematic — at best naïve and at worst manipulative-by working to conceal Beth's role in what Tyler's responses are and how they are organized. We need to be aware of the epistemic violence (Spivak 1999, 266) that such a claim to transparency commits while staying clear of a romanticized view of particular subject positions that assumes purity of experience (Harding 1992; Stone-Mediatore 2016). Tyler is also socially situated.

So instead of a naïve removal of self from the scene and claim to giving voice, we might recognize, acknowledge, and be reflective about the very specific positions from which one speaks. This could bring about the deepest sense of responsibility in the sense of acknowledging and embracing the intra-active positions from which stories are made and remade:

And the risk in representing them is not that the intellectual would speak for a "subaltern subject that that can know and speak itself"; it is, rather, that there may be no trace of this "subject's itinerary" at all (Spivak 1999: 272). Thus, it is not that the representing intellectual or other elite must step aside for the subaltern to speak. Quite the opposite, for the subaltern to be heard, representation-in the sense of picturing-is required. Indeed, the subaltern cannot speak, but neither can anyone else if speaking is conceived as the direct transmission between subjects in a face-to-face encounter. (Disch 2016: 793)

- Clare Hemmings $(2010,22)$ notes that Spivak consistently warns us of the individual author-blaming that mitigates against real recognition of historically and discursively constituted speaking locations. 
Beth's responsiveness does not end with her talking to Tyler and staging an encounter with a larger audience. Neither can she remove her critical role in shaping the stories by simply not editing Tyler's responses. It is disingenuous to assume that the stories speak for themselves. For Beth, being responsive involves, rather, acknowledging her presence, listening in a manner that allows reshaping her own questions and approach, as well as actively collaborating with Tyler and her other partners to make sure that their stories are coming through in a manner that conveys their meaning. Responsiveness is not about elimination but rather recognition of the vulnerability and uncertainty of the situation. It includes openness, on Beth's part, to actually collaborate with Tyler to shape his story. This might indeed involve active editorial work in collaboration with Tyler and assuming responsibility for the final form. It is only responsible if Beth is as vulnerable and involved in the encounters of others with the stories and in the uses to which they are put.This is in contrast to what many attempts at collecting, sharing, and archiving stories appear to share: a conception of the efforts as giving voice to and staging the encounters of the "other."

If we understand doing justice to stories in terms of responsiveness, it is clear that what matters most is not giving voice but rather a renewed attentiveness to the act of listening. Listening to recorded stories can similarly be understood through the concept of a story scene, taking careful account of its particular qualities inclusive of questions about who, what, where, and why. For digital stories, we must ask: Who can have access to the stories and under what circumstances? Does the gallery, the web, the archive, or an entirely other venue serve best for staging encounters with these stories? How can their partial and contingent nature be captured? How can the different ways that the mediated interaction is broken be eliminated? Can we even possibly limit or deny access in some circumstances or design for a kind of layered interaction that prevents broken or piecemeal listening? Ethical themes of reciprocity, responsiveness, and communion can be extended to digital story scenes for thinking through the relational qualities of tellers (who are not present) and listeners.

Far from being ready-made commodities of exchange, stories are made and remade in the very particular and fleeting moments of encounter. And so doing justice to stories at least entails acknowledging and embracing the vulnerability, fragility, and uncertainty that permeate the whole, and attending to the act of listening (perhaps even more so than that of collecting and archiving made possible with digital technologies). The desire to be narrated, and our dependence on each other for our stories, also leads to recognition of the political nature of story scenes. Far from being inherently negative, we might find this a space of possibility by committing ourselves to the other in the act of listening. Storytelling, not unlike theory, aims at depicting experiences and as such it should be continually reassessed by a plurality of readers and storytellers.

${ }^{10}$ Both Booth (1988) and Stone-Mediatore (2016) argue eloquently for this continual assessment of stories from two very different starting points. 


\title{
Communion
}

\author{
There is more than a verbal tie between the words common, \\ community, and communication. What we must have in common \\ in order to form a community or society are aims, beliefs, aspirations, \\ knowledge- a common understanding. \\ John Dewey, Democracy and Education
}

Returning to the idea of the valence and possibilities inherent in the vulnerability, fragility, and uncertainty of relationships within story scenes, we must remember that what makes practices of storytelling and listening worthwhile is their ability to expand the experiences of the storyteller and listener. Any attempt to communicate an experience in a qualitatively accurate and detailed manner changes one's own attitude and understanding of the experience as well as that of the listener. It is not hard to imagine how the understanding of what's at stake changes, for both Beth and Tyler, as a result of their conversation. In fact, what matters for Beth, Tyler, and everyone else who is participating in Beth's project is whether and how the process as a whole might extend and deepen their individual and collective understanding of the issues that the community is facing, serving as an environment in which to think through possible courses of action in response.

Indeed, if "the desire to be seen, to be recognized, is the paradoxical desire created by oppression" (Oliver 2001, 24), Beth's success in collecting the stories of this community may be a testament to fundamental injustices. It is the situation of suffering (Hargraves, Breslin, and JafariNaimi 2015) that conjoins Beth, Tyler, and others in the activity of storytelling and listening. The work of stories is not just to record and document or to make different voices heard. Rather, the practice of storytelling and listening works to draw out what the situation is and the action it demands (JafariNaimi, Nathan, and Hargraves 2015).

If we understand storytelling and listening as more than encounters that render individual accounts and personal experiences visible, and (re)consider the practices of storytelling and listening as dialogic and thus the most basic mode of civic action, we can understand storytelling and listening as forms of individual and social inquiry. In this way, Beth's project is potentially more than a repository of stories or chronicling a set of perspectives and events. The issue at stake is not about speaking about, speaking for, or representing the community, either. The task is rather to ask questions that meaningfully address the issue at hand: the waste site that threatens the dignity of individuals and the livelihood of the community. Together, it is their task to trace the many stories, putting them in conversation in a process of questioning what matters and how they can move forward in the here and now of the situation in which they find themselves. We might then take seriously Beth's statement that she has a better appreciation of what the community is going through. In this case, we may consider not only whether this appreciation might shape the immediate form and treatment of the exhibition and the archive, but also whether the archive and exhibition is a meaningful step 
forward at all. We might question what this new appreciation entails for deepening her commitment or for collective action.

In this manner, what Beth and Tyler are involved in is a form of conversational inquiry that unites practical and theoretical aims. The challenge is to cultivate the practices of storytelling and listening in their potential for a renewed (collective) understanding of what's at stake as well as a conception and commitment to possible courses of action that might resist and challenge its injustices. The practical question of action in response to the situation is intertwined with theoretical and historical questions such as ones that help trace the historical roots of the issue at hand; the social, economic, and cultural forces at work; or a rethinking of the dominate narratives that frame the situation."

Reorientation toward the issue is also potentially critical for the forms of collective action that may ensue from it. We can begin to conceive story scenes as more than a context for the exchange of information or a stage for encounters with the "other" and performances of the self, but rather ultimately as a medium and an environment with active tendencies (Dewey 1916, 14). This is a definition that renders stories as more than communicative processes of information exchange or modes of performative expression. Rather, stories should be understood as inseparable from their story scenes, including their historical, social, and political backdrops and their immediate and implied audiences. As media, they are to be understood as "those conditions that might promote or hinder, stimulate or inhabit the characteristic activities" of those involved (ibid). So, we might ask, how might the characteristic activities of Beth, Tyler, and everyone else be transformed by the practices of storytelling and listening in which they partake, and vice versa? How do storied interactions make and remake Beth, Tyler, and their individual and collective understanding of what's at stake?

Therein lies a third way of understanding what we owe to stories, one that I refer to as communion, gesturing toward democratic participation in shared aims, values, and interests in a manner that entails a shared commitment to various modes of individual/collective action. Doing justice to stories takes its starting point in a commitment to the issue at hand, to the situation of suffering. It finds its fulfillment in what Kim TallBear (2014) refers to as "standing with." Communion transcends the bounds of a reciprocal contract or responsive encounter toward development of a lasting commitment.

Communion rests-in theory and practice-on collapsing the binaries of self and other, insider and outsider, story and story scene, telling and listening. Communion is not a naïve mode of building consensus toward a predefined course of action. It is also not meant to suggest a romantic or arbitrary view of community that renders differences or disagreements invisible or irrelevant. Rather, it is an invitation to the messy entanglements and to embrace the intra-actional

"Within this understanding may lie many strategies for moving forward, including a kind of strategic essentialism described by Ehlers $(2016,355)$ as "the ways marginalized groups may need to use essentialism - that is, the flattening of differences in identification-as a short-term tactic to forge a sense of collective political identity in order to secure certain political sense." It is in this sense that together Beth and her participants may decide to "use" the stories as a spectacle or political argument toward social justice. In this manner, stories may continue to do their work as artful self-presentations even after their authors no longer find them entirely authentic to their evolving characters and experiences. 
nature of relationships (cf. Barad 2007) and the dialogical form of storytelling and listening. It speaks to a commitment and devotion to an ongoing troubling (Haraway 2016) of the assumptions, dominant narratives, and predefined modes of action inclusive of those that animate digital storytelling initiatives. Such an ethics "is not about right or correct responsibility to a radically exteriorized other, but about responsibility and accountability for the lively relationalities of becoming of which we are a part" (Barad 2007, 393).

\section{Beginnings}

It is this dialogue between comrades that is a gesture of love. bell hooks, Choosing the Margin as a Space of Radical Openness

The dominant framing of digital storytelling practices as a form of empowerment is deeply problematic, especially when we consider how activities of storytelling and listening may indeed be oppressive, advancing age-old practices of extraction and colonization in new guises. Such strategies risk taking away from what is meaningful and worthwhile in experiences of storytelling and listening by tokenizing and using stories for political purposes without reaching the kinds of conversations, understandings, and commitments that is their potential. ${ }^{\prime 2}$ A renewed attentiveness to story scenes understood in their full technical, economic, social, and political texture is key for restoring what is meaningful and worthwhile in practices of storytelling and listening.

Staging an encounter with the "other" may be a starting point for seeing phenomena anew, sharing in another's experience, finding out what we have in common, and even arriving at a better understanding of our selves. Archiving stories is worthwhile as it allows us to have records and accounts of past and present. Collectively stories may also be powerful tools of political dissent, revealing patterns of shared experiences and injustices. Yet, partial and disengaged encounters can reinforce existing prejudices and stereotypes or create misunderstandings. They deepen certainty in ones' own positions and reinforce a dismissive attitude that reduces accounts of experience to individual matters of opinion with no grounds for assessing their relevance to the matters of concern.

Situations of storytelling and listening differ greatly from one instance to another. My aim here has been to highlight commonly held assumptions to sharpen the attentiveness to justice, which is arguably the driving principle of many digital storytelling practices. There are no simple recipes or predefined blueprints for making them just. Reciprocity, responsiveness, and communion are beginnings for a more nuanced understanding of ethics and politics of these

12 While the focus of this article is on practices of collecting, sharing, and archiving stories, the arguments have relevance for other forms of collaboration between those working in the contexts of well-established institutions and people who reside outside of them. Within design and HCI discourses, practices of participatory and co-design are representative given their dominant tropes of giving voice and empowerment. 
practices in part by questioning and collapsing the seemingly rigid boundaries self and other, story scene and story, telling and listening.

\section{Author Biography}

Nassim Parvin (formerly JafariNaimi) is an Assistant Professor of Digital Media in the School of Literature, Media, and Communication at Georgia Tech. Parvin's research explores the ethical and political dimensions of design and technology, especially as related to values of democratic participation and social justice.

\section{Acknowledgements}

I am deeply grateful to my colleagues and mentors Anne Pollock, Mary McDonald, Jennifer Singh, Janet Murray, and Ian Hargraves for their generous and thoughtful feedback on drafts of this paper. I would also like to thank the anonymous reviewers and the editors at ESTS, especially Katie Vann, for their helpful comments and suggestions.

\section{References}

Ahmed, Syed Ishtiaque, Steven J. Jackson, Nova Ahmed, Hasan Shahid Ferdous, Md. Rashidujjaman Rifat, A. S. M. Rizvi, Shamir Ahmed, and Rifat Sabbir Mansur. 2014. "Protibadi: A Platform for Fighting Sexual Harassment in Urban Bangladesh." In Proceedings of the 32nd Annual ACM Conference on Human Factors in Computing Systems, pp. 2695-2704. ACM.

Barad, Karen. 2007. Meeting the Universe Halfway: Quantum Physics and the Entanglement of Matter and Meaning. Durham, NC: Duke University Press.

Bardzell, Shaowen, and Jeffrey Bardzell. 2011. "Towards a Feminist HCI Methodology: Social Science, Feminism, and HCI." In Proceedings of the SIGCHI Conference on Human Factors in Computing Systems, pp. 675-684. ACM.

Booth, Wayne C. 1988. The Company We Keep: An Ethics of Fiction. Berkeley, CA: University of California Press.

Bowker, Geoffrey C. 2005. Memory Practices in the Sciences. Cambridge, MA: MIT Press.

Butler, Judith. 2005. Giving an Account of Oneself. New York: Oxford University Press.

Capel, Tara, Jennyfer Lawrence Taylor, and Dhaval Vyas. 2016. “Using Self-Reported Experiences to Explore the Issues of Women in Crisis Situations." In Proceedings of the 28th Australian Conference on Computer-Human Interaction, pp. 483-488. ACM.

Callison, Candis. 2014. How Climate Change Comes to Matter: The Communal Life of Facts. Durham, NC: Duke University Press.

Couldry, Nick. 2008. "Mediatization or Mediation? Alternative Understandings of the Emergent Space of Digital Storytelling." New Media \& Society 10, no. 3: 373-391. 
Couldry, Nick, Richard MacDonald, Hilde Stephansen, Wilma Clark, Luke Dickens, and Aristea Fotopoulou. 2015. "Constructing a Digital Storycircle: Digital Infrastructure and Mutual Recognition." International Journal of Cultural Studies 18, no. 5: 501-517.

Cavarero, Adriana. 2014. Relating Narratives: Storytelling and Selfhood. New York: Routledge.

Clarke, Rachel, Peter Wright, Madeline Balaam, and John McCarthy. 2013. "Digital Portraits: Photo-Sharing after Domestic Violence." In Proceedings of the SIGCHI Conference on Human Factors in Computing Systems, pp. 2517-2526. ACM.

Costanza-Chock, Sasha. 2011. "Digital Popular Communication: Lessons on Information and Communication Technologies for Social Change from the Immigrant Rights Movement." National Civic Review 100, no. 3: 29-35.

Chin, Elizabeth. 2016. My Life with Things: The Consumer Diaries. Durham, NC: Duke University Press.

Dewey, John. 1916. Democracy and Education. New York: Macmillan.

Disch, Lisa. 2016. "Representation." In The Oxford Handbook of Feminist Theory, 781-802, edited by Lisa Disch and Mary Hawkesworth. New York: Oxford University Press.

Dimond, Jill P., Michaelanne Dye, Daphne LaRose, and Amy S. Bruckman. 2013. "Hollaback!: The Role of Storytelling Online in a Social Movement Organization." In Proceedings of the 2013 Conference on Computer Supported Cooperative Work, pp. 477-490. ACM.

Dombrowski, Lynn, Ellie Harmon, and Sarah Fox. 2016. "Social Justice-Oriented Interaction Design: Outlining Key Design Strategies and Commitments." In Proceedings of the 2016 ACM Conference on Designing Interactive Systems, pp. 656-671. ACM.

Durrant, Abigail, David S. Kirk, and Stuart Reeves. 2014. "Human Values in Curating a Human Rights Media Archive." In Proceedings of the 32nd Annual Conference on Human Factors in Computing Systems, pp. 2685-2694. ACM.

Ehlers, Nadin. 2016. "Identities." In The Oxford Handbook of Feminist Theory, 346-366, edited by Lisa Disch and Mary Hawkesworth, New York: Oxford University Press.

Forlano, Laura. 2017. "Data Rituals in Intimate Infrastructures: Crip Time and the Disabled Cyborg Body as an Epistemic Site of Feminist Science." Catalyst: Feminism, Theory, Technoscience 3, no. 2.

Foster, Laura A. 2017. Reinventing Hoodia: Peoples, Plants, and Patents in South Africa. Seattle, WA: University of Washington Press.

Frank, Arthur W. 2010. Letting Stories Breathe: A Socio-Narratology. Chicago, IL: University of Chicago Press.

Fox, Sarah, and Christopher Le Dantec. 2014. "Community Historians: Scaffolding Community Engagement through Culture and Heritage." In Proceedings of the 2014 Conference on Designing Interactive Systems, pp. 785-794. ACM.

Haraway, Donna. 2016. Staying with the Trouble: Making Kin in the Chthulucene. Durham, NC: Duke University Press.

Harding, Sandra. 1992. "Rethinking Standpoint Epistemology: What Is "Strong Objectivity?" The Centennial Review 36 (3): 437-470. 
Hargraves, Ian, Maggie Breslin, and Nassim JafariNaimi. 2015. “Shared Decision Making Called for by the Situation of Suffering." Mayo Clinic. https: / / shareddecisions.mayoclinic.org/2015/08/05/ shared-decision-making-calledfor-by-the-situation-of-suffering/

Harrison, Jane, Lesley MacGibbon, and Missy Morton. 2001. "Regimes of Trustworthiness in Qualitative Research: The Rigors of Reciprocity." Qualitative Inquiry 7, no. 3: 323-345.

Hemmings, Clare. Why Stories Matter: The Political Grammar of Feminist Theory. Next Wave. Durham, NC: Duke University Press.

Herron, Daniel, Nazanin Andalibi, Oliver Haimson, Wendy Moncur, and Elise van den Hoven. 2016.“HCI and Sensitive Life Experiences." In Proceedings of the 9th Nordic Conference on Human-Computer Interaction 134. ACM.

hooks, bell. 1989. "Choosing the Margin as a Space of Radical Openness." Framework: The Journal of Cinema and Media 36: 15-23.

JafariNaimi, Nassim, Lisa Nathan, Ian Hargraves. 2015. "Values as Hypotheses: Design, Inquiry, and the Service of Values." Design Issues 31 (4): 90-103.

Jain, S. Lochlann. 2013. Malignant: How Cancer Becomes Us. Berkeley, CA: University of California Press.

Kottman, Paul A. 2014. Translator's Introduction to Relating Narratives: Storytelling and Selfhood, by Adriana Cavarero, vii-xxv. New York: Routledge.

Lambert, Joe. 2013 [2006]. Digital Storytelling: Capturing Lives, Creating Community. New York: Routledge.

Light, Ann, and Yoko Akama. 2012. "The Human Touch: Participatory Practice and the Role of Facilitation in Designing with Communities." In Proceedings of the 12th Participatory Design Conference: Research Papers-Volume 1, pp. 61-70. ACM.

Loukissas, Yanni, and Anne Pollock. 2017. "After Big Data Failed: The Enduring Allure of Numbers in the Wake of the 2016 US Election." Engaging Science, Technology, and Society 3: 16-20.

Lupton, Deborah. 2014. “The Commodification of Patient Opinion: The Digital Patient Experience Economy in the Age of Big Data." Sociology of Health \& Illness 36, no. 6: 856-869.

Nathan, Lisa P., Michelle Kaczmarek, Maggie Castor, Shannon Cheng, Raquel Mann. 2017. "Good for Whom?: Unsettling Research Practice." In Proceedings of the 8th International Conference on Communities and Technologies, pp. 290-297. ACM.

Oliver, Kelly. 2001. Witnessing: Beyond Recognition. Minneapolis, MN: University of Minnesota Press.

Seigfried, Charlene Haddock. 1996. Pragmatism and Feminism: Reweaving the Social Fabric. Chicago, IL: University of Chicago Press.

Smith, Linda Tuhiwai. 2013. Decolonizing Methodologies: Research and Indigenous Peoples. London, UK: Zed Books Ltd.

Sontag, Susan. 2003. Regarding the Pain of Others. New York: Farrar, Straus and Giroux.

Spivak, Gayatri Chakravorty. 1999. A Critique of Postcolonial Reason: Toward a History of the Vanishing Present. Cambridge, MA: Harvard University Press. 
Stone-Mediatore, Shari. 2016 "Storytelling/Narrative." In The Oxford Handbook of Feminist Theory, edited by Lisa Disch and Mary Hawkesworth. New York: Oxford University Press.

Strohmayer, Angelika, Mary Laing, and Rob Comber. 2017. "Technologies and Social Justice Outcomes in Sex Work Charities: Fighting Stigma, Saving Lives." In Proceedings of the 2017 CHI Conference on Human Factors in Computing Systems, pp. 3352-3364, ACM.

Subramaniam, Banu. 2014. Ghost Stories for Darwin: The Science of Variation and the Politics of Diversity. Chicago, IL: University of Illinois Press.

TallBear, Kim. 2014. "Standing with and Speaking as Faith: A Feminist-Indigenous Approach to Inquiry." Journal of Research Practice 10, no. 2: 17.

Taylor, Alex S. 2011. "Out There." In Proceedings of the SIGCHI Conference on Human Factors in Computing Systems, pp. 685-694. ACM.

Turkle, Sherry. 2016. Reclaiming Conversation: The Power of Talk in a Digital Age. New York: Penguin.

Wylie, Sara Ann. 2018. Fractivism: Corporate Bodies and Chemical Bonds. Durham, NC: Duke University Press. 